\title{
Argumentação em espaços educativos não-formais: um curso de extensão para mediadores em Centro de Divulgação Científico e Cultural
}

\author{
Lea da Silva Veras ${ }^{1}$
}

Salete Linhares Queiroz ${ }^{2}$

\begin{abstract}
Resumo
A argumentação está entre os processos desejáveis em espaços educativos devido à sua estreita ligação com a construção do conhecimento e do pensamento crítico. No presente trabalho são relatadas atividades desenvolvidas em um curso de extensão ministrado em Centro de Divulgação Científica e Cultural tendo em vista a formação de mediadores para a promoção de diálogos argumentativos. A fundamentação teórica que subsidiou o delineamento das atividades é também apresentada, assim como as percepções dos mediadores frente ao curso. Assim, o artigo pretende contribuir para o progresso de discussões sobre a formação de mediadores de museus e centros de ciências no âmbito argumentativo.

Palavras-chave: Mediação; CDCC; Centros de Ciências; Argumentação; Curso de Extensão.
\end{abstract}

\section{Argumentation in informal learning environments: an outreach workshop for the explainers in a science} center

\begin{abstract}
Argumentation is among the most valuable communication processes one would like to trigger in educative spaces due to its close relationship to learning construction and critical knowledge. Considering this, we describe the activities developed in an outreach workshop in a Science Center, which had the goal of training explainers to promote argumentative dialogues. The theoretical foundations that supported the activities are also discussed, as well as the perceptions of the mediators with respect to the workshop. The article intends to contribute to the discussion on argumentative training of explainers in science centers.

Keywords: Mediation; CDCC; Science Centers; Argumentation; Outreach Workshop.
\end{abstract}

\section{Introdução}

Museus e centros de ciências são espaços educativos não formais essenciais à divulgação e popularização das ciências. Nessa perspectiva, a Universidade de São Paulo conta com o Centro de Divulgação Científica e Cultural (CDCC), localizado na cidade de São Carlos, com o intuito de estabelecer vínculo ativo entre a universidade e a sociedade. No local, alunos da Universidade de São Paulo atuam como mediadores desempenhando a importante tarefa de recepcionar o público visitante e levá-lo a interagir com os diversos aparatos aí localizados, assim como de

\footnotetext{
${ }^{1}$ Universidade de São Paulo (USP), São Carlos, leaveras@gmail.com

2 Universidade de São Paulo (USP), São Carlos, salete@iqsc.usp.br
} 
acompanhá-lo em visitas externas, com o propósito de discutir aspectos que permeiam as ciências da natureza e a matemática. Para promover o entendimento real do que está em discussão, cabe aos mediadores tanto a detenção do conhecimento adequado sobre os aspectos abordados quanto utilizar ferramentas que os levem a suscitar um diálogo frutífero com o público. Apesar da importância desse diálogo, cursos de extensão ou de capacitação voltados para a elaboração de estratégias e reflexões que conduzam à melhoria da articulação de processos comunicativos desses mediadores são escassos.

A argumentação está entre os processos comunicativos desejáveis de desencadeamento em espaços educativos, devido à sua estreita ligação com a construção do conhecimento. Vários autores destacam a sua influência em tal construção, assim como no exercício da reflexão e do pensamento crítico (BARGALLÓ; PRAT, 2010; CAPECCHI; CARVALHO,2000; JUNIOR et al., 2012). Nesse contexto, a formação dos mediadores na perspectiva do fomento à ocorrência de diálogos argumentativos em espaços dessa natureza é promissora na medida em que pode enriquecer o cabedal de conhecimentos dos visitantes e incentivá-los ao pensamento crítico e à reflexão.

A mediação amparada pelo diálogo argumentativo contrapõe-se a uma mera demonstração do que se encontra em exibição. A primeira pretende envolver os visitantes no assunto em foco por meio de perguntas, provocar discussões e elucidar as dúvidas advindas das mesmas. Já na demonstração, o mediador fala quase todo o tempo e o principal objetivo é apresentar o conteúdo, algumas vezes de uma forma engessada, que nem sempre é adaptada ao perfil do público presente.

Embora vários educadores destaquem a relevância da ocorrência da argumentação no contexto do ensino formal e reportem distintas estratégias para fomentá-la em salas de aula (BARGALLÓ; PRAT, 2010; CAPECCHI; CARVALHO, 2000; JUNIOR et al., 2012), até onde vai o nosso conhecimento não existem trabalhos similares voltados ao contexto do ensino não formal, na perspectiva da promoção da argumentação durante as visitas aos museus e centros de ciências. Apesar de autores como Stuchi e Ferreira (2003) enfatizarem a relevância da interatividade nos museus e do treinamento de mediadores para o alcance desse objetivo, iniciativas de capacitação que conduzam ao aprimoramento das habilidades dos mediadores na promoção de diálogos argumentativos não são recorrentes na literatura. 


\section{HSF HORIZONTES}

Este trabalho tem como objetivo relatar atividades desenvolvidas em um curso de extensão ocorrido no Centro de Divulgação Científica e Cultural da USP tendo em vista a formação de mediadores para a promoção de diálogos argumentativos. Além disso, a fundamentação teórica que subsidiou o delineamento das mesmas é também apresentada. Assim, o artigo pretende contribuir para o preenchimento dessa lacuna no que diz respeito a propostas de capacitação de mediadores de centros de ciências no âmbito argumentativo.

\section{Participantes do curso de extensão e atuação no Centro de Divulgação}

Mediadores do Centro de Divulgação e demais interessados da comunidade tiveram a oportunidade de ingressar no curso de extensão, com carga horária de 40 horas-aula, ministrado no intervalo de uma semana. Antes do início das atividades os inscritos responderam a um questionário de caracterização online. No total, foram dezenove respondentes que participaram de todas as atividades, dos quais um vinculado ao Museu e Centro de Ciências, Educação e Artes "Luiz de Queiroz" e os demais ao próprio Centro de Divulgação. O questionário teve como objetivo coletar informações pessoais como nome, idade, gênero, e-mail de contato, curso na Universidade de São Paulo e ano de ingresso e atuação no centro de ciências, além de percepções sobre o tópico em foco no curso.

Os mediadores que realizaram o curso são, em sua maioria, graduandos da Universidade de São Paulo (94,7\%), incluindo uma estudante de ciências biológicas do campus de Piracicaba, e o gênero feminino mais comum $(73,7 \%)$. A idade média dos participantes é de 22 anos e dentre eles há predominância de alunos do curso de estatística $(31,6 \%)$. Isso provavelmente ocorre porque este é oferecido em período noturno, facilitando a realização das atividades dos alunos no Centro de Divulgação, que ocorrem majoritariamente em período diurno. Como no local não há atividades vinculadas diretamente ao aprendizado de estat ística, esses mediadores têm o desafio de aprender tópicos com os quais não lidam no curso universitário. Tal situação também é vivenciada por outros mediadores, pois não há, necessariamente, correspondência entre o curso de graduação e a área de atuação no Centro de Divulgação. De fato, dentre os mediadores: três atuavam no Setor de Química (dois graduandos em química e um em engenharia ambiental); quatro no Setor de Biologia (dois 


\section{HSF H O R I ON TES}

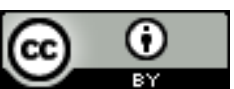

BY
RELATO

DOI: https://doi.org/10.24933/horizontes.v38i1.687

graduandos em estatística, um em engenharia ambiental e uma graduada em ciências biológicas); seis no Setor de Exposições de Ciências (quatro graduandos em estatística, um em matemática e um em engenharia elétrica); quatro no Observatório Astronômico (dois graduandos em física e dois em licenciatura em ciências exatas); e um no Setor de Audiovisual (graduando de engenharia elétrica).

Um número considerável de mediadores ingressou na Universidade de São Paulo no ano anterior ao curso de capacitação de mediadores $(31,6 \%)$ e a grande maioria $(68,4 \%)$ ingressou nos três anos anteriores ao curso. Ou seja, a atuação como mediador permeia diferentes momentos da graduação dos mesmos, com uma concentração em recém-ingressos. A maioria $(52,6 \%)$ dos mediadores iniciou o trabalho no Centro de Divulgação há não mais que um semestre. O número de mediadores cuja experiência como tal é apenas proveniente do próprio Centro de Divulgação é de 63,2\%.

\section{Delineamento das atividades do curso de extensão: referencial teórico}

Para o delineamento das atividades do curso de extensão, foi levado em consideração o exposto no Quadro 1. Este resulta de uma pesquisa de Simon, Erduran e Osborne (2006) que buscou identificar ações a partir das quais os professores inserem a argumentação na sua prática pedagógica, doravante denominadas de ações pró-argumentação. Na perspectiva do presente trabalho foi assumido que, para que atingisse os seus objetivos, o curso deveria, entre outros aspectos, permitir que os mediadores vivenciassem momentos favoráveis ao desencadeamento de ações dessa natureza.

Periódico Horizontes - USF - Itatiba, SP - Brasil - e020018 
Quadro 1 - Categorias de ações pró-argumentação de Simon, Erduran e Osborne (2006), adaptadas ao contexto do curso de extensão

\begin{tabular}{|c|c|}
\hline $\begin{array}{l}\text { Categorias de ações } \\
\text { pró-argumentação }\end{array}$ & $\begin{array}{l}\text { Declarações/afirmações/solicitações do formador do curso de extensão para } \\
\text { desencadeamento dos processos argumentativos }\end{array}$ \\
\hline \multirow{2}{*}{ Falar e ouvir } & Incentiva a discussão entre os mediadores \\
\hline & la os mediadores a escutarem as opiniões dos colegas \\
\hline \multirow{2}{*}{$\begin{array}{l}\text { Conhecer o significado do } \\
\text { argumento }\end{array}$} & Define argumento \\
\hline & Apresenta exemplos de argumer \\
\hline \multirow{3}{*}{$\begin{array}{l}\text { Posicionar-se na construção } \\
\text { dos argumentos }\end{array}$} & Encoraja a apresentação das ideias dos mediadores \\
\hline & Incentiva os mediadores a se posicionarem na apresentação das suas ideias \\
\hline & Valoriza diferentes pontos de vista dos mediadores \\
\hline \multirow{5}{*}{$\begin{array}{l}\text { Justificar com base em } \\
\text { fundamentação teórica }\end{array}$} & Avalia ou confere se as justificativas são subsidiadas por fundamentação teórica \\
\hline & Fornece fundamentação teórica que subsidie as ideias dos mediadores \\
\hline & Solicita justificativas para as conclusões dos mediadores \\
\hline & Enfatiza a importância de apresentação de justificativas \\
\hline & $\begin{array}{l}\text { Estimula a apresentação de novas justificativas em adição às apresentadas } \\
\text { inicialmente }\end{array}$ \\
\hline Construir argumentos & $\begin{array}{l}\text { Elabora estratégias de ensino-aprendizagem que permitam a solicitação aos } \\
\text { mediadores da construção de argumentos na forma escrita e oral }\end{array}$ \\
\hline Avaliar argumentos & $\begin{array}{l}\text { Incentiva a avaliação dos argumentos pelos mediadores e a reflexão sobre o que } \\
\text { é necessário para a construção de um bom argumento, considerando as } \\
\text { evidências que o sustentam }\end{array}$ \\
\hline $\begin{array}{l}\text { Contra-argumentar/ } \\
\text { Debater }\end{array}$ & $\begin{array}{l}\text { Incentiva a contra-argumentação frente a argumentos apresentados pelos } \\
\text { colegas mediadores, inclusive durante a realização de debates e interpretações } \\
\text { de papel (role-play) }\end{array}$ \\
\hline \multirow{2}{*}{$\begin{array}{l}\text { Refletir sobre o processo de } \\
\text { argumentação }\end{array}$} & $\begin{array}{l}\text { Estimula a reflexão sobre os processos adotados pelos mediadores para a } \\
\text { construção do argumento }\end{array}$ \\
\hline & $\begin{array}{l}\text { Questiona os mediadores sobre as mudanças nas suas opiniões, decorrentes dos } \\
\text { processos adotados para a construção do argumento }\end{array}$ \\
\hline
\end{tabular}

Fonte: Simon, Erduran e Osborne (2006) adaptado pelas autoras

Vale ressaltar que enquanto o quadro original elenca as ações realizadas em sala de aula (2006), neste trabalho é considerado o contexto de um ambiente não formal de ensino de um centro de ciências. Ou seja, foram feitas adaptações do quadro de um ambiente formal de ensino para um não formal, no qual o formador do curso protagonizou papel semelhante ao do professor em sala de aula. Assim, as atividades foram planejadas de modo a que o maior número de elementos que favorecessem o desencadeamento de ações pró-argumentação fosse contemplado ao longo do curso.

\section{Atividades de formação de mediadores no curso de extensão}

Durante o curso de extensão foi realizado um conjunto de cinco atividades distintas, tendo em vista o desencadeamento de ações pró-argumentação, conforme mencionado 
anteriormente. Nessa perspectiva, buscou-se a difusão de conhecimentos acerca de elementos que suportam uma boa argumentação, assim como de ações potencialmente capazes de promovê-la.

\section{Jogo Argumentativo}

Com o intuito de mostrar aos mediadores os componentes essenciais de um argumento, segundo Toulmin (2003), foi aplicado no curso um jogo argumentativo. Para a sua realização, os mediadores foram divididos em grupos e, como em todo jogo, foi oferecido um prêmio à equipe vencedora. Cada equipe trabalhou na elaboração de um bom argumento sobre o porquê do merecimento a uma caixa de bombons de chocolate, o prêmio. Foi esclarecido que as razões para merecerem o prêmio poderiam ser reais ou imaginárias, formais ou informais, direcionadas para um membro da equipe ou à equipe inteira.

A execução da tarefa constituiu inicialmente em cada grupo redigir os argumentos e selecionar um porta-voz para apresentá-los. Esgotado o período de trinta minutos, cada grupo apresentou suas razões para merecer o prêmio. Após a apresentação dos grupos, foram discutidas definições e apresentados exemplos de componentes do argumento. Com o apoio dessa discussão e do material usado para tal, os mediadores tentaram identificar a existência desses componentes nos argumentos por eles produzidos.

Por fim, a formadora apresentou o resultado da análise dos argumentos formulados por cada um dos grupos em slides, segundo Toulmin (2003), de modo a permitir a visualização das similaridades e diferenças nos argumentos usados pelos diferentes grupos, assim como a qualidade dos mesmos. Finalmente foi divulgado o grupo vencedor.

A aplicação do jogo argumentativo primou por engajar os mediadores nas seguintes ações pró-argumentação: Falar e ouvir, em especial na discussão entre membros de um mesmo grupo para a definição dos argumentos que seriam apresentados para justificar o merecimento à caixa de chocolate e na escuta da opinião dos colegas de outras equipes na defesa dos seus argumentos, com o mesmo intuito; Conhecer o significado do argumento, a partir da discussão sobre os componentes do argumento, segundo o Modelo de Toulmin (2003), que culminou na indicação do grupo vencedor do jogo; Posicionar-se na construção dos argumentos, ao exigir dos 
mediadores a apresentação das ideias que subsidiaram a construção dos argumentos para o merecimento do prêmio diante de todos os membros das demais equipes; Construir argumentos, a partir da preparação prévia, por escrito, e posterior apresentação oral dos argumentos de cada grupo que justificassem o merecimento do prêmio; Avaliar argumentos, na medida em que realizaram o exercício de associação entre os componentes dos argumentos que haviam construído e aqueles considerados essenciais, segundo o Modelo de Toulmin (2003), o que proporcionou a reflexão sobre o que é necessário para a construção de um bom argumento.

\section{Elaboração de Perguntas}

Os tipos de perguntas elaboradas em salas de aula de ciências são alvo de atenção de vários pesquisadores (MACHADO; SASSERON, 2012; SILVA, 2002), existindo aqueles que entendem a formulação de questões como uma maneira de constituir sentidos (SILVA, 2002) e os que consideram a pergunta como o estímulo inicial às interações discursivas (MACHADO; SASSERON, 2012), dentre outras compreensões. O exercício de reflexão por parte dos professores sobre os questionamentos que oferecem aos seus alunos é, portanto, relevante. De fato, tal exercício traz em seu bojo a possibilidade de instrumentalizá-los para a promoção de diálogos que, a depender do seu desenvolvimento, assumem caráter argumentativo.

$\mathrm{Na}$ perspectiva do curso de extensão, um exercício de reflexão sobre as perguntas elaboradas pelos mediadores durante as visitas foi realizado, tendo em vista o fornecimento de subsídios para torná-los cientes da diversidade das mesmas e do importante papel que podem assumir no cotidiano dos centros de ciências. Na realização da atividade, denominada Elaboração de Perguntas, a formadora solicitou aos mediadores que, divididos nos mesmos grupos da atividade anterior, indicassem perguntas que faziam aos visitantes. Em seguida, foi realizada uma discussão sobre o trabalho de Machado e Sasseron (2012), que classifica perguntas usualmente elaboradas em aulas investigativas de ciências, em: perguntas de problematização; perguntas sobre dados; perguntas exploratórias sobre o processo; e perguntas de sistematização.

Após a discussão, a formadora solicitou que, na medida do possível, cada grupo classificasse as perguntas indicadas de acordo com a proposta de Machado e Sasseron (2012). 
Para tanto, a descrição da classificação das perguntas foi adaptada ao contexto de um ambiente não formal de ensino de um centro de ciências, conforme ilustra o Quadro 2.

Concluída a classificação, foram feitas ponderações sobre a sua pertinência à luz das considerações presentes no trabalho dos autores. Os exemplos de perguntas sugeridas pelos mediadores para cada uma das categorias propostas também estão elencados no Quadro 2.

Quadro 2 - Classificação e descrição de perguntas, segundo Machado e Sasseron (2012), com os respectivos exemplos indicados pelos mediadores

\begin{tabular}{|c|c|c|}
\hline $\begin{array}{l}\text { Classificação de } \\
\text { Perguntas }\end{array}$ & Descrição & $\begin{array}{l}\text { Algumas perguntas indicadas pelos } \\
\text { mediadores }\end{array}$ \\
\hline $\begin{array}{l}\text { Perguntas de } \\
\text { problematização }\end{array}$ & $\begin{array}{l}\text { Ajudam os visitantes a buscar explicações e } \\
\text { organizar informações para uma situação } \\
\text { com a qual se deparam no ambiente não } \\
\text { formal de ensino e exploram os } \\
\text { conhecimentos que já possuem sobre }\end{array}$ & $\begin{array}{l}\text { Por que existem quatro estações no ano? } \\
\text { Por que as estrelas brilham? } \\
\text { Qual a aparência de um planeta visto no céu? } \\
\text { Em qual fase da Lua podemos ter um eclipse } \\
\text { lunar? }\end{array}$ \\
\hline $\begin{array}{l}\text { Perguntas sobre } \\
\text { dados }\end{array}$ & $\begin{array}{l}\text { Abordam dados envolvidos em situação com } \\
\text { a qual os visitantes se deparam no ambiente } \\
\text { não formal de ensino. Direcionam o olhar dos } \\
\text { visitantes para as variáveis neles envolvidas } \\
\text { relacionando-as, comparando ideias, } \\
\text { propondo inversões e mudanças }\end{array}$ & $\begin{array}{l}\text { Comparando os dois modelos de produção } \\
\text { agrícola, o convencional e o agroecológico, } \\
\text { qual vocês acham que é o mais sustentável? } \\
\text { Como estimamos a idade de uma estrela? } \\
\text { (observe os elementos que seu espectro } \\
\text { emite) } \\
\text { Sabemos que os polos chegam a ficar até três } \\
\text { meses sem receber a luz solar. Como isso é } \\
\text { possível? }\end{array}$ \\
\hline $\begin{array}{l}\text { Perguntas } \\
\text { exploratórias } \\
\text { sobre o processo }\end{array}$ & $\begin{array}{l}\text { Buscam que os visitantes emitam suas } \\
\text { conclusões sobre situação com a qual se } \\
\text { deparam no ambiente não formal de ensino. } \\
\text { Podem demandar a formulação de } \\
\text { hipóteses, justificativas, explicações, } \\
\text { conclusões como forma de sistematizar seu } \\
\text { pensamento na emissão de uma enunciação } \\
\text { própria. Buscam concretizar o aprendizado } \\
\text { na situação proposta }\end{array}$ & $\begin{array}{l}\text { E se eu... (trocasse a ordem dos anéis)? } \\
\text { Alguém sabe o que isso significa? } \\
\text { O que vocês poderiam fazer pra melhorar...? } \\
\text { Dá para acender uma lâmpada sem ligá-la na } \\
\text { energia? } \\
\text { Quando chove transborda? } \\
\text { Como construímos um telescópio? }\end{array}$ \\
\hline $\begin{array}{l}\text { Perguntas de } \\
\text { sistematização }\end{array}$ & $\begin{array}{l}\text { Buscam que os visitantes apliquem o } \\
\text { conceito em discussão em outros contextos } \\
\text { e prevejam explicações em situações } \\
\text { diferentes da apresentada pelo problema }\end{array}$ & $\begin{array}{l}\text { Sabe-se que o eclipse solar, ocorre em fase } \\
\text { de Lua nova e o eclipse lunar em fase cheia. } \\
\text { Sabe-se também que em todos os meses } \\
\text { temos ambas as fases. Qual o motivo que não } \\
\text { nos permite apreciar a ocorrência de eclipses } \\
\text { todos os meses? }\end{array}$ \\
\hline
\end{tabular}

Fonte: Machado e Sasseron (2012) adaptado pelas autoras

A aplicação da atividade de elaboração de perguntas primou por engajar os mediadores nas seguintes ações pró-argumentação: Falar e ouvir, com ênfase na discussão entre membros de um mesmo grupo para a definição das perguntas que seriam apresentadas para exemplificar 
os questionamentos elaborados nas visitas e na classificação das perguntas de acordo com Machado e Sasseron (2012); Posicionar-se na construção dos argumentos, ao exigir dos mediadores a apresentação e defesa da classificação assumida pelo grupo para as referidas perguntas; Justificar com base em fundamentação teórica, a partir do fornecimento, por parte da formadora, de artigo publicado em revista com seletiva política editorial (MACHADO; SASSERON, 2012), para subsidiar as propostas de classificação das perguntas elaboradas pelos mediadores.

\section{Compartilhamento de Postagens em Blog}

A leitura de textos relacionados com a formação de mediadores em museus de ciência e com processos comunicativos, em particular a argumentação, em espaços educativos formais e não formais de ensino (Quadro 3) serviu de base para a realização de atividade desenvolvida no blog do curso de extensão.

Quadro 3 - Textos utilizados na atividade realizada no blog do curso de extensão

\begin{tabular}{cl}
\hline & \multicolumn{1}{c}{ Artigo } \\
\hline 1 & $\begin{array}{l}\text { MONTEIRO, I. C. C.; M. A. A. MONTEIRO; A. GASPAR, Atividades experimentais de demonstração e o } \\
\text { discurso do professor no ensino de física, IV Encontro Nacional Pesquisa em Educação em Ciências. } \\
\text { (2003) 1-11. }\end{array}$ \\
2 & $\begin{array}{l}\text { FERREIRA, T. ET AL., Formação de monitores do Museu de Ciências da DICA: preparo além da prática, XI } \\
\text { Encontro de Pesquisa em Ensino Física. (2008) 1-8. }\end{array}$ \\
3 & $\begin{array}{l}\text { DE MARCHI, B. A. C.; A. C. RoCHA COSTA; R. MORAES, CV-Muzar : um ambiente de apoio à aprendizagem } \\
\text { informal em museus através de um entendimento do aprender baseado na comunicação e na } \\
\text { linguagem, VIII Congresso Iberoamericano de Informática Educativa (2006). }\end{array}$ \\
& $\begin{array}{l}\text { RICCI, F. P.; S. L. F. TRIVELATO, Investigando argumentos em explicações de um estudo do meio, VIII } \\
\text { Encontro Nacional de Pesqui em Educação em Ciências. (2011). }\end{array}$ \\
& $\begin{array}{l}\text { ROCHA, L. M.; C. S. MACHADO, Museu Fórum: meio ambiente em debate, XIV Encontro Nacional de } \\
\text { Pesquisa em Ciência da Informação (2013). }\end{array}$ \\
\hline
\end{tabular}

Fonte: elaborado pelas autoras

Os textos indicados no Quadro 3 foram disponibilizados no blog do curso e cada mediador ficou responsável pela leitura de um texto e a elaboração e postagem de duas perguntas no blog sobre o assunto nele abordado. O Quadro 4 apresenta o enunciado das solicitações feitas no blog pela formadora. 
Quadro 4 - Enunciado da atividade de leitura e compartilhamento de postagens no blog do curso de extensão

Sobre a atividade a ser desenvolvida na oficina de leitura

Escolher um texto e formular duas questões que julgue de interesse para o desencadeamento de discussões no contexto do Curso de Formação de Mediadores (pelo menos uma delas deve estar relacionada com a questão da argumentação) e postá-las no blog. Em seguida, solucionar as questões apresentadas por dois dos colegas no blog (ou seja, você responderá 4 questões). ATENÇÃO: as questões formuladas não devem ter resposta óbvia/direta no texto. Ou seja, estas precisam exigir, por parte do leitor, um processo de reflexão na construção da sua resposta.

Fonte: elaborado pelas autoras

Após essa primeira etapa, os mediadores acessaram novamente o blog e escolheram duas perguntas elaboradas por um dos colegas, às quais responderam com base na leitura do texto relacionado às questões. Concluída esta etapa de elaboração de perguntas e respostas no blog, uma discussão foi realizada de maneira a possibilitar a análise e complementação das respostas oferecidas pelos mediadores no blog.

A atividade de leitura e compartilhamento de postagens no blog primou por engajar os mediadores nas seguintes ações pró-argumentação: Falar e ouvir, tendo em vista a necessidade que os mediadores tiveram de postar perguntas, na forma escrita, assim como respostas aos questionamentos elaborados pelos colegas; Conhecer o significado do argumento, a partir da leitura e discussão de textos que tinham como foco principal a questão da argumentação. $O$ texto 1, por exemplo, define diferentes tipos de argumentação, enquanto no texto 4 os autores lançam mão do Modelo de Toulmin (2003) para investigar a construção de argumentos no ensino de ciências; Posicionar-se na construção dos argumentos e Justificar com base em fundamentação teórica, ao exigir dos mediadores a defesa dos pontos de vista que foram assumidos nas respostas postadas no blog. Nesse contexto, a formadora esclareceu que as respostas precisavam estar devidamente justificadas e em sintonia com os conteúdos dos textos aos quais elas se referiam.

\section{O Problema do Looping: Discussão do Vídeo na Perspectiva da Promoção da Argumentação}

A exibição do vídeo O Problema do Looping, produzido pelo Laboratório de Pesquisa e Ensino de Física da Universidade de São Paulo, subsidiou a discussão de estratégias potencialmente promotoras da argumentação. Inicialmente os mediadores assistiram ao vídeo 
e, em seguida, divididos nas mesmas equipes da atividade de jogo argumentativo, elencaram as estratégias que fomentaram a argumentação no ambiente formal nele ilustrado. Em seguida, propuseram estratégias que poderia ter efeito similar em ambientes não formais de ensino.

A formadora coordenou discussões de modo a provocar reflexões sobre as estratégias propostas pelos mediadores na perspectiva de aplicação nos centros de ciências, sendo elas: criar um roteiro de perguntas que não demandem apenas respostas diretas, mas que provoquem contestações durante a visita; discutir teorias e experimentos desenvolvidos por cientistas em que a existência de erros acabou por auxiliar no avanço científico; trazer à tona opiniões opostas de cientistas frente a um mesmo assunto, por meio de relato de situações históricas; realizar atividades experimentais investigativas durante visitas escolares; estimular debates em atividades específicas promovidas no Centro de Divulgação (por exemplo, uma vez que o Cineclube exibe filmes com temáticas distintas, promover debates, finalizada a sessão); pedir para que os professores, anteriormente à visita, façam uma breve introdução em sala de aula sobre assuntos que serão abordados no Centro de Divulgação.

A aplicação da atividade de exibição do vídeo e reflexão sobre estratégias promotoras da argumentação primou por engajar os mediadores nas seguintes ações pró-argumentação: Falar e ouvir, a partir da discussão que deu margem para que as estratégias fossem propostas pelos mediadores e avaliadas na perspectiva do propósito assumido; Posicionar-se na construção dos argumentos, ao exigir dos mediadores a apresentação das ideias que pautaram a proposição das estratégias e que se posicionassem frente às mesmas; Justificar com base em fundamentação teórica, ao solicitar que os mediadores justificassem seus posicionamentos amparados em ponderações e observações extraídas do referido vídeo, no qual a argumentação é fomentada.

\section{Produção de Vídeo e de Blog}

A produção de um produto midiático (vídeo) e de um espaço midiático (blog) sobre questões que permeiam a atuação dos mediadores no Centro de Divulgação foi solicitada com o intuito de engajá-los em discussões que demandassem tomadas de decisão e fornecessem indícios sobre as suas percepções a respeito das atividades que aí realizam. Nessa perspectiva, os mediadores foram distribuídos em dois grupos, um deles com a incumbência de produção do 
vídeo e outro do blog, que deveriam ser compartilhados na aula de encerramento do curso.

Com relação à produção de vídeo, doze mediadores definiram livremente o roteiro e o papel de cada um na gravação, assim como o processo de edição final do material. Determinados tais aspectos, a proposta foi apresentada aos mediadores do grupo responsável pela produção do blog, que deveriam opinar sobre o seu mérito e viabilidade de execução, além de sugerir modificações e melhorias, se fosse o caso. O vídeo produzido, com tempo duração de $15 \mathrm{~min} 37 \mathrm{~s}$, conta com a atuação de cinco mediadores, que aparecem em diversas oportunidades. Os demais mediadores ficaram responsáveis pela captação de imagem, de som, elaboração das falas dos atores e direção da gravação. Tomadas as decisões sobre as cenas que seriam mantidas e as que seriam eliminadas na edição final, um dos mediadores fez a inclusão de títulos e sincronização de imagem e som.

O vídeo traz, primeiramente, entrevistas com transeuntes na área próxima ao Observatório do Centro de Divulgação, inicializadas com a pergunta $O$ que você espera de um monitor? (o termo monitor equivale ao termo mediador). Com as entrevistas, realizadas com seis pessoas, foram buscados conhecimentos sobre as interações discursivas e as ações dos mediadores que contribuem para o sucesso ou fracasso de uma visita, a partir de concepções da população sobre a atuação dos mesmos. Na sequência, o vídeo apresenta quatro situações fictícias de abordagem de visitantes aos mediadores.

Para cada uma das visitas interpretadas, é mostrado o atendimento às abordagens de forma incorreta e correta, na perspectiva dos produtores do vídeo: na primeira situação dois visitantes chegam ao Setor de Exposições de Ciências do Centro de Divulgação, sendo recebidos por dois mediadores; na segunda, um desses visitantes segue em direção aos experimentos de física do Setor, acompanhado por um dos mediadores; na terceira, o outro visitante dirige-se ao Jardim da Percepção, acompanhada da segunda mediadora; na quarta, os dois visitantes encontram uma terceira mediadora no Observatório.

Com relação à produção do blog, sete mediadores discutiram livremente sobre o papel que seria desempenhado por um espaço midiático dessa natureza na divulgação das atividades realizadas no Centro de Divulgação, as suas características e o conteúdo que veicularia. Assim como mencionado anteriormente, determinados tais aspectos, a proposta foi apresentada aos mediadores do grupo responsável pela produção do vídeo, que deveriam opinar sobre o seu 


\section{HSF H O R I ON TES}

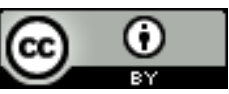

mérito e viabilidade de execução, além de sugerir modificações e melhorias, se fosse o caso.

Estabelecidas as regras de escrita e postagem do blog, os mediadores optaram por um tema que dispõe o seu conteúdo de forma organizada em três áreas: o topo, com a identificação da página pelo título Aprender+Diversão (Figura 1); a área principal contendo as publicações; e a barra lateral com os links para outros sites de museus e as publicações da própria página.

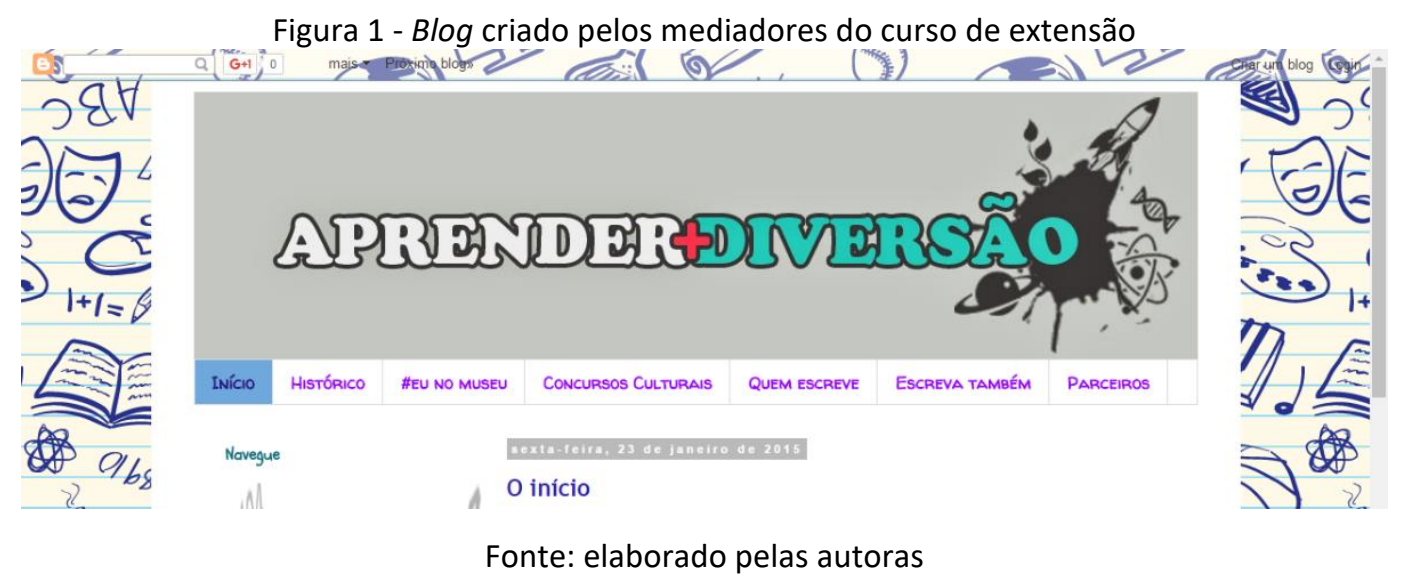

Conforme ilustra a Figura 1, o produto apresenta menus superiores que indicam tanto a intenção de fornecer informações para a população como a de compartilhar experiências. Com efeito, a inserção do menu Histórico e do menu Concursos Culturais reflete a intenção de mostrar o desenvolvimento do Centro de Divulgação ao longo do tempo e a sua importância na comunidade, com ênfase para a promoção de olimpíadas e ações culturais. Com a inserção do menu \#Eu no Museu os mediadores valorizam a interação com os visitantes, a partir da intenção de coletar as suas percepções sobre experiências vivenciadas no Centro de Divulgação. No menu Parceiros a intenção é valorizar e incentivar o estabelecimento de parceiras com empresas que conduzam à arrecadação de fundos, permitindo a intensificação das atividades oferecidas para a comunidade.

O menu Quem Escreve visa à divulgação dos nomes e da biografia dos mediadores que colaboram na construção do blog. No menu Escreva Também, os mediadores convidam professores e outros colaboradores para a escrita de material a ser divulgado blog. No menu lateral, links de museus e centros de ciências, inclusive do próprio Centro de Divulgação, são disponibilizados. O menu Início traz os posts em ordem cronológica e o primeiro expressa a 


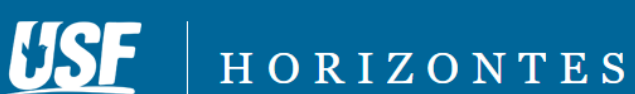

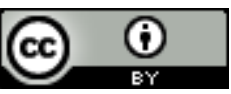

intenção dos mediadores com a criação do blog.

A aplicação da atividade de confecção de vídeo e blog primou por engajar os mediadores nas seguintes ações pró-argumentação: Falar e Ouvir, na discussão entre membros de um mesmo grupo para a definição do roteiro do vídeo e da elaboração do blog e, em especial, durante a comunicação das decisões tomadas aos membros do outro grupo para avaliação da sua pertinência; Posicionar-se na construção de argumentos, ao exigir dos mediadores a apresentação e argumentação a favor das ideias que subsidiaram a construção das propostas para a produção dos materiais em questão.

O Quadro 5 sintetiza todas as atividades do curso e permite a visualização do tempo requerido para a realização de cada uma delas. Cada dia foi ocupado por cinco horas de atividades.

Quadro 5 - Distribuição das atividades do curso de extensão

\begin{tabular}{|c|c|c|c|c|c|}
\hline & Dia 1 & Dia 2 & Dia 3 & Dia 4 & Dia 5 \\
\hline \multirow{2}{*}{$\frac{2 \pi}{\frac{2 \pi}{c}}$} & \multirow{2}{*}{$\begin{array}{l}\text { Aula expositiva } \\
\text { dialogada }\end{array}$} & $\begin{array}{c}\text { Compartilhamento } \\
\text { de postagens em } \\
\text { blog }\end{array}$ & $\begin{array}{c}\text { Compartilhamento } \\
\text { de postagens em } \\
\text { blog }\end{array}$ & $\begin{array}{l}\text { Produção de vídeo } \\
\text { e de blog }\end{array}$ & $\begin{array}{c}\text { Aula expositiva } \\
\text { dialogada }\end{array}$ \\
\hline & & $\begin{array}{l}\text { Compartilhamento } \\
\text { de postagens em } \\
\text { blog }\end{array}$ & $\begin{array}{l}\text { Produção de vídeo } \\
\text { e de blog }\end{array}$ & Vídeo LAPEF & $\begin{array}{l}\text { Produção de vídeo } \\
\text { e de blog }\end{array}$ \\
\hline \multirow{2}{*}{$\frac{0}{\frac{0}{0}}$} & Jogo argumentativo & Jogo argumentativo & Vídeo LAPEF & $\begin{array}{l}\text { Produção de vídeo } \\
\text { e de blog }\end{array}$ & Vídeo LAPEF \\
\hline & $\begin{array}{c}\text { Aula expositiva } \\
\text { dialogada }\end{array}$ & $\begin{array}{c}\text { Elaboração de } \\
\text { perguntas }\end{array}$ & $\begin{array}{l}\text { Produção de vídeo } \\
\text { e de blog }\end{array}$ & $\begin{array}{c}\text { Produção de vídeo } \\
\text { e de blog }\end{array}$ & $\begin{array}{l}\text { Questionário de } \\
\text { avaliação do curso }\end{array}$ \\
\hline
\end{tabular}

Fonte: elaborado pelas autoras

Cabe destacar que, além das atividades mencionadas anteriormente, a formadora ministrou aulas expositivas dialogadas nas quais os mediadores eram constantemente instigados a argumentar e contra-argumentar sobre temas que incluíram a visão do brasileiro acerca da ciência e tecnologia (CGEE, 2015) e a atuação de mediadores no cenário nacional e internacional.

\section{Percepções dos mediadores quanto ao curso de extensão}

Finalizadas as atividades, dezoito mediadores responderam a um questionário de avaliação, de forma anônima, com relação às suas percepções quanto ao curso oferecido. Este 
solicitava a indicação de uma dentre as quatro possíveis respostas de satisfação: excelente, bom, regular, ruim. São as seguintes as afirmações: 1. Clareza em relação aos objetivos do curso; 2 . Concordância entre os objetivos anunciados e o que foi realmente estudado no curso; 3. Encadeamento dos conteúdos do curso (ordem de apresentação dos conteúdos); 4. Leituras recomendadas; 5. Aulas expositivas dialogadas; 6. Discussões em sala; 7. Exercícios em grupo (exemplo: jogo argumentativo); 8. Produção de vídeo e de blog; 9. O curso como um todo.

Na Figura 2 o eixo x corresponde à numeração das afirmações citadas anteriormente e o eixo y corresponde à frequência em percentual das respostas dos mediadores fornecidas às afirmações.

Figura 2 - Valores em porcentagem da frequência das respostas dos mediadores fornecidas às perguntas do questionário de avaliação

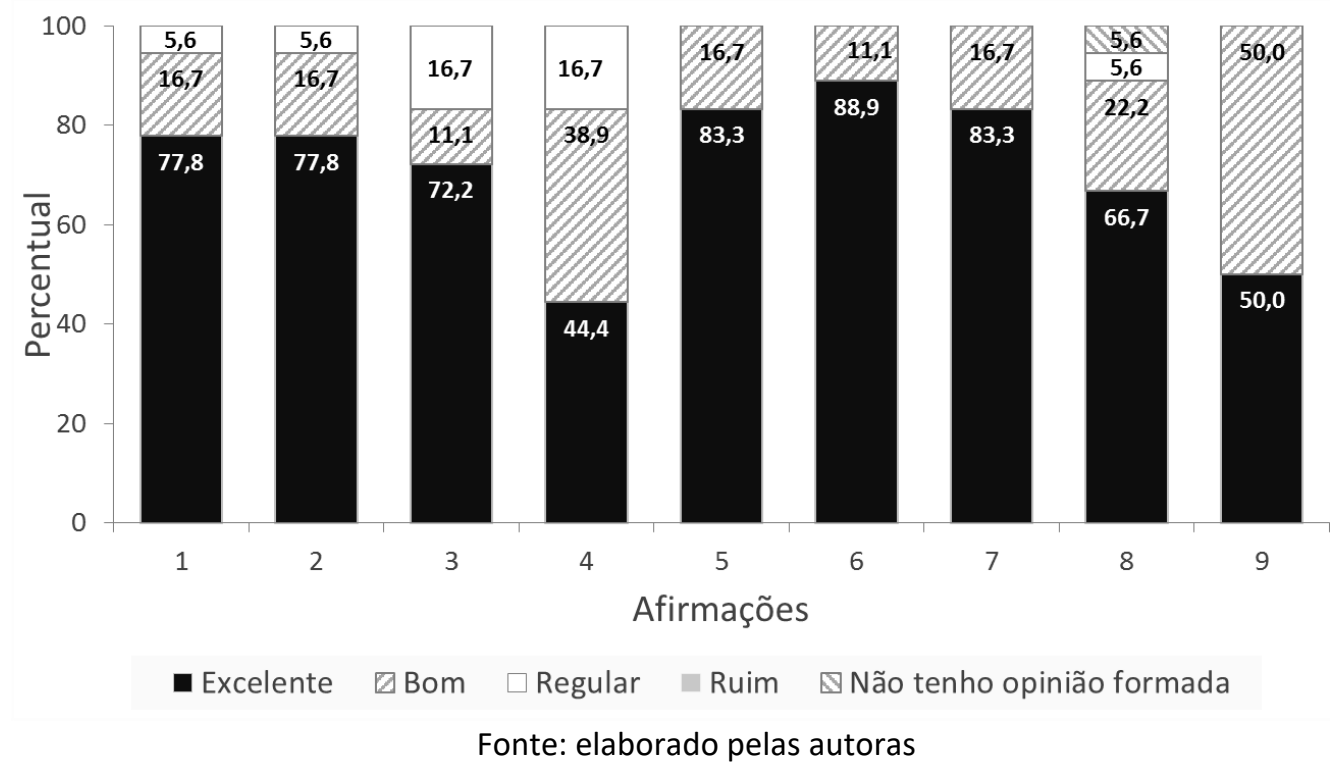

Nas afirmações de 1 a 3 os mediadores opinaram sobre aspectos relacionados à coerência entre as ações programadas para o curso e a sua efetivação. Os resultados foram positivos, principalmente com relação à clareza dos objetivos do curso e o que foi nele abordado $(94,5 \%$, somatório das respostas excelente e bom, em ambos os casos).

Nas afirmações de 4 a 8 os mediadores opinaram sobre os elementos e estratégias que foram arregimentados para a execução do curso. É possível verificar que eles foram bastante favoráveis à participação nas aulas expositivas dialogadas, nas discussões em sala e nos 
exercícios em grupo. Com efeito, para as três afirmações o somatório das respostas excelente e bom foi $100 \%$. Em contraponto, a atividade que envolveu a leitura de textos não encontrou a mesma receptividade, com a sua indicação como sendo regular por $16,7 \%$ dos monitores. A produção de vídeo e de blog foi também respaldada pela maioria dos monitores, embora 11,2\% a tenham considerado como regular ou não possuíam opinião formada sobre. Por fim, cabe acrescentar que o curso, como um todo, foi considerado excelente ou bom pela totalidade dos participantes (somatório das respostas para a afirmação 9).

Os mediadores foram ainda solicitados a apresentar pontos considerados positivos e negativos no desenvolvimento do curso, assim como sugestões para o seu aprimoramento. Em quinze comentários feitos com relação aos aspectos positivos foi destacado o estímulo à integração entre eles. Outros nove comentários citaram a atividade de criação de blog e vídeo, enquanto seis comentários apontaram o aperfeiçoamento da habilidade de argumentação. Seis comentários chamaram a atenção para a importância das temáticas abordadas.

Menções à ludicidade das atividades também ocorreram, existindo ainda a percepção de que o curso foi, de fato, devotado à formação dos participantes. Em resumo, e nas palavras de um dos mediadores, o curso foi "Dinâmico, Legal e Didático".

Em onze comentários feitos com relação aos aspectos negativos foi destacada a distribuição de todas as atividades em apenas uma semana, gerando cansaço. Estes vieram acompanhados de sugestão de realização das próximas versões do curso de maneira menos condensada.

\section{Considerações finais}

Apesar do recorrente uso da mediação humana em espaços educativos não formais, poucas são as iniciativas reportadas na literatura que visam à formação de profissionais para a função. Não são poucas as habilidades mobilizadas para execução desse papel, dentre as quais está o estabelecimento de diálogos com os visitantes. Nessa perspectiva, no presente trabalho foram discutidas atividades realizadas em um curso de extensão que teve como objetivo formar mediadores para a promoção de diálogos argumentativos. Para tanto, a formadora, além de promover a aproximação dos mediadores com referenciais teóricos que fornecem suporte a uma 
abordagem argumentativa durante as visitas, primou por desencadear ações definidas no escopo do texto como ações pró-argumentação.

Dentre as referidas ações destacaram-se as que levaram os mediadores a discutir e escutar as opiniões dos colegas e a apresentar e posicionar-se na apresentação das suas ideias. Foi também fornecida fundamentação teórica que subsidiasse as referidas ideias e que os permitissem conhecer o significado do argumento, assim como avaliar a sua qualidade e refletir sobre os componentes essenciais que viabilizam tal construção. Ademais, algumas das estratégias de ensino-aprendizagem permitiram que a formadora solicitasse aos mediadores, de forma explícita, a construção de argumentos, seja na forma escrita, seja na forma oral.

A caracterização dos mediadores corroborou a importância do curso de extensão para a sua formação, já que são alunos que, em sua maioria, ingressaram recentemente na Universidade de São Paulo, cujas experiências nessa função são restritas ao Centro de Divulgação. O que sugere ter sido única na trajetória acadêmica de cada um deles a oportunidade de refletir sobre as temáticas abordadas no curso.

\section{Referências}

BARGALLÓ, C. M.; PRAT, A. Favorecer la argumentación a partir de la lectura de textos. Didáctica de las Ciencias Experimentales, v. 63, p. 39-49, 2010.

CAPECCHI, M. C. V. M.; CARVALHO, A. M. P. Argumentação em uma aula de conhecimento físico com crianças na faixa de oito a dez anos. Investigações em Ensino de Ciências, v. 5, n. 3, p. 171-189, 2000.

CENTRO DE GESTÃO E ESTUDOS ESTRATÉGICOS (CGEE). Percepção pública da ciência e tecnologia 2015 - Ciência e tecnologia no olhar dos brasileiros. Sumário executivo, Brasília: Centro de Gestão e Estudos Estratégicos, 2015.

JUNIOR, P. D. C.; LOURENÇO, A. B.; SASSERON, L. H.; CARVALHO, M. P. Ensino de física nos anos iniciais: análise da argumentação na resolução de uma "atividade de conhecimento físico". Investigações em Ensino de Ciências, v. 17, n. 2, p. 489-507, 2012.

MACHADO, V. R.; SASSERON, L. H. As perguntas em aulas investigativas de ciências: a construção teórica de categorias, Revista Brasileira de Pesquisa em Educação em Ciências, v. 12, n. 2, p. 29-44, 2012. 
SILVA, H. C. Discursos e leituras da física na escola: uma abordagem introdutória da síntese newtoniana para o ensino médio. 2002. 234f. Tese (Doutorado) - Faculdade de Educação, Universidade Estadual de Campinas, Campinas, 2002.

SIMON, S.; S. ERDURAN; OSBORNE, J. Learning to teach argumentation: research and development in the science classroom, International Journal of Science Education, v. 28, n.2-3, p. 235-260, 2006.

STUCHI, A. M.; FERREIRA, N. C. Análise de uma exposição científica e proposta de intervenção, Revista Brasileira de Ensino de Física, v. 25, n. 2, p. 207-217, 2003.

TOULMIN, S. E., The uses of argument, Cambridge University Press, Cambridge, 2003.

\section{AGRADECIMENTOS}

O presente trabalho foi realizado com apoio do Centro de Divulgação Científica e Cultural da Universidade de São Paulo (CDCC-USP).

Recebido em julho 2018.

Aprovado em março 2020. 